\title{
Households' public library use across the school calendar
}

\section{Authors: Gregory Gilpin and Anton Bekkerman}

(C) This manuscript version is made available under the CC-BY-NC-ND 4.0 license https:// creativecommons.org/licenses/by-nc-nd/4.0/.

Gilpin, Gregory, and James Becker. "Households' public library use across the school calendar." Library \& Information Science Research 42, no. 2 (April 2020). doi: 10.1016/j.lisr.2020.101012. 


\title{
Households' public library use across the school calendar Gregory Gilpin* and Anton Bekkerman
}

\author{
Department of Agricultural Economics and Economics, Montana State University, 306 Linfield \\ Hall, P.O. Box 172920, Bozeman, MT 59717, United States. \\ * Corresponding author. E-mail address: gregory.gilpin@montana.edu.
}

\begin{abstract}
When schools are on break, some households may be constrained to provide educational resources to their children. Public libraries could be low-cost providers of materials and services that foster educational investment. This research extends existing literature by combining household-level data-public library checkout counts, residential property tax assessment values, student enrollment rosters, and distance to public library measures - to conduct a panel analysis of public library use across the public school calendar. The empirical analyses find that public-school breaks generally impact library use for households with children in public school, but not for households without children in public school or for the lowest socioeconomic status households with children in public school. Distance to library is found to be negatively correlated with public library use for all households, but differentially and dependent on households' socioeconomic status and structure. Lastly, community events and weather are identified to impact use.
\end{abstract}

\section{Acknowledgements}

This work was supported by the National Leadership Grants program [CDFA Number 45.312] administered by the Institute of Museum and Library Sciences. We thank comments and suggestions provided at the 2017 Federal Reserve System Community Development Research Conference, 2016 Association for Education Finance and Policy Annual Meetings, 2016 Southern Economics Association Annual Meetings, and 2016 Western Economic Association International Annual Meetings that greatly improved this research. 


\section{Introduction}

Substantial educational losses can occur during school breaks (Heyns, 1978; Cooper, Nye, Charlton, Lindsay, \& Greathouse, 1996; Downey, von Hippel, \& Broh, 2004). Moreover, student achievement losses have been shown to be concentrated primarily among students who do not participate in supplemental learning opportunities, leading to lasting impacts on high school track placements, high school completion, and four-year college attendance (Alexander, Entwisle, \& Olson, 2007; Cornelius \& Semmel, 1982). Consequently, programs that encourage the continuation of learning outside of school environments - such as summer school, public library reading clubs, and independent curricula - improve learning outcomes by engaging children in educational activities.

The ability to participate in and benefit from learning activities outside of school may be unequally distributed across students due to households' socioeconomic backgrounds and time constraints. Existing research has predominately found that students from middle socioeconomic classes tend to increase learning outcomes in subsequent school assessments after summer breaks, but that learning outcomes for students from lower socioeconomic classes tend to either stagnate or decrease (Cooper et al., 1996; Quinn, 2015; Gershenson, 2013).

Public libraries provide free access to proprietary educational information; have trained staff who can identify and locate specific educational content; host continuing education programs for individuals of all ages; and, libraries are perhaps an especially important resource for lower-income households and those with children. Moreover, libraries are nearly ubiquitous across communities with nearly 17,000 outlets across the United States in 2015 . The structured information transfer frameworks that exist in public libraries provide educational supplement during periods of school breaks for households with children. 


\section{Problem statement}

Several researchers have investigated patrons' public library use, but often data is crosssectional and do not have dynamic, intertemporal dimensions. Adding a time component permits a more thorough investigation of patrons' habit formation, community events, seasonal variations, public school enrollment, and local public-school calendars. Moreover, panel analysis permits the use of individual fixed effects in model specifications that eliminate sample selection concerns.

The public library use literature has focused much attention on differences across racial characteristics, and gaps remain in analysis of households across socioeconomic status and household familial structure. Understanding households' public library use may be informative to better design public policies and library accessibility for individuals within communities.

This study outlines an empirical methodology for improving the measurement of public library use and increases the empirical literature on public library use. In particular, this research outlines a new data collection process, highlights new data sources, and then provides empirical evaluations of household familial structure, socioeconomic status, community events in proximity to the public library, and weather on households' public library use across the publicschool calendar.

Using these new data and methodologies, this paper seeks to assess four objectives. First, the research develops a baseline empirical assessment of what factors influence households' decisions to increase or decrease their use of public library resources. Second, the baseline model is used to understand whether households with children use the public library differently when public schools are on breaks. Third, the paper determines how public library use differs across households' different socioeconomic status. Finally, the work combines lessons from these three 
sets of empirical results to propose several public library management strategies for increasing engagement between libraries and their stakeholders.

\section{Literature review}

While research of public library use has not rigorously assessed factors that may affect patrons' demand for public libraries across periods when public schools are in session, there are a number of studies that focus on understanding how demographic and socioeconomic characteristics play a role. Insights from these works help build the foundation for developing a baseline model of households' public library use behaviors, from which methodological extensions that incorporate information about public school calendars can be developed.

\subsection{Demographic and Socioeconomic Factors Affecting Public Library Use}

Public libraries serve patrons of varying socioeconomic and demographic backgrounds. Among these are children who receive much of their focus. This is evidenced in U.S. public libraries with $34 \%$ of circulation being categorized as material for children, $63 \%$ of all public library programming targeting children, and 70\% of program participants attend children's programs (Institute of Museum and Library Sciences, 2015; Joo \& Cahill, 2019). Similarly, households with children are more likely to visit the library (Sin \& Kim, 2008) and use the library (Hemmeter, 2006). ${ }^{1}$

The public library use literature has also investigated how family characteristics are associated with library use. Chen, Rea, Shaw, and Bottino (2016) interview 200 parents of

\footnotetext{
${ }^{1}$ Researchers continue to study the impact of public library early childhood programming on child development. See Kewish (1979), McKenzie and Stooke (2012), Peterson et al (2012), Goulding and Crump (2017), and Cahill, Joo, and Howard (2019).
} 
children ages six- to 18-months-old in a pediatric clinic and find that public library use and reading aloud are positively related, suggesting that parents with preferences toward reading are more likely to use public libraries. This increased use of the public library with those with preferences toward reading is well known, and researchers have found that patrons' years of education is one of the most impactful determinants of library use (Kronus, 1973). Interestingly, Agosto, Paone, and Ipock (2008) find no significant gender differences in the reasons for using libraries in a small sample of adolescents who visit one of two public libraries. Thus, it may be that adolescent males and females use similar amounts of library resources, just at different visitation rates.

Paradoxically, demographic characteristics impact public library visitation frequency and do not necessarily align with patrons' educational attainment. For example, Clark and Hawkins (2011) find that while family affluence does not deter public library use, white students use libraries the least among racial categories. Similar results are obtained by Hemmeter (2006) and Sin-Ching (2012) who find that 12th grade students who identify as ethnic minorities use public libraries more than those who identify as white. Using GIS analysis to investigate patrons' travel distance to public libraries, Park (2012) estimates whites are willing to travel the farthest, whereas African Americans and Hispanics are more sensitive to travel distance. This may imply that minority groups are constrained to use the most convenient library branch despite its resource availability and services, whereas Whites are able to travel to public library branches with larger collections and program options. Burke (2007) finds that library use to be significantly less for Native Americans than Whites. Analyzing Internet use, Bishop, Tidline, Shoemaker, and Salela (1999) show that the majority of African American women in Chicago have never used a computer outside of their home and that only $9 \%$ have Internet access at home. 
They suggest that public libraries could reduce the digital divide by offering increased access to computers and the Internet. Lastly, homeless men report using public libraries as a safe place and enjoy reading and computer access (Hodgetts, Stolte, Chamberlain, Radley, Nikora, Nabalarua, \& Groot, 2008).

A small collection of literature aims to study the role of public library use by immigrants. Similar to non-immigrant populations, educational attainment has a positive relationship with public library use across all immigrant groups in the United States (Burke, 2008). From interviews of U.S. library directors, Vårheim (2011) finds that library programs targeting immigrants were successful in establishing returning users. These programs include English classes, as well as courses in computer use and civics. Madrigal, Cubillas, Yaden, Anamarie, Brassell, \& Tam (1999) establish a book loan program at a child care center in an inner-city Latino neighborhood to encourage reading in both Spanish and English over one year. The researchers estimate that book checkouts increased from 1.5 to 16 books per day with $70 \%$ of eligible children checking out books.

\subsection{Summer learning loss and summer public library use literature}

The literature on public library use by families with children indicate that summer learning may benefit students in the following school year. In her seminal book, Heyns (1978) finds that both low socioeconomic status (SES) students and high SES students make similar gains in vocabulary in seventh grade. However, high SES students make up to four months of gains in vocabulary over the summer, while low SES students decrease (for Caucasians) or remain stagnant (for African Americans) in their vocabulary knowledge. Heyns suggests summer reading as a significant mechanism by which this achievement gap develops. Similarly, Kim 
(2004) uses measures of the number of books a child has read and finds that reading four to five books over the summer may mitigate decline in fall reading scores. Kim finds that children who reported easier access to books at a library also read more books, suggesting that libraries may play an important role in student achievement.

Children's public library programming during summer has been found to impact student achievement in subsequent school years. In one of the earliest studies to empirically evaluate the effectiveness of children's programs, Goldhor and McCrossan (1966) show that membership to a public library's summer reading club is positively related to fall test scores. A caveat to this result is that prior reading ability and spring test scores impact fall test scores substantially more than club membership.

There may also exist socioeconomic and demographic divisions between the users and non-users of summer reading programs. In a three-year panel study, Bogel (2012) finds that while students who participated in a summer reading program at a public library experienced either no change or gains in reading ability relative to their peers, the majority of the program participants were Caucasian female students above the poverty line. The empirical analysis may have suffered from sample selection issues. Merga and Roni (2017) provide evidence of selective use of public libraries suggesting females tend to spend more free time at the public library than males.

\section{Methodology}

The existing literature helps form the initial structure for modeling patron use preferences and behaviors toward public library use. This paper uses this structure to inform the data collection process, the data construction process, and the baseline empirical model specifications, 
from which an extension that adds public school calendar information is constructed.

\subsection{Data overview}

Five distinct data sources are combined to characterize weekly household-level public library use: patrons' weekly public library use counts, residential property tax assessment values, public school enrollment rosters, local community events calendars, and measurements of weather. The data are collected within a Montana micropolitan area served by a public library system and a public-school district. ${ }^{2}$ For confidentiality, the location is not disclosed. In this micropolitan area, there is only one central public library with no bookmobiles or branches, implying that patrons' library use data reported within this area are complete as they are not affected by borrowing materials at other library systems and that patrons must physically visit the public library to access physical materials.

Some library materials, such as eBooks and audiobooks, have become accessible remotely through the Internet across the U.S. over the last decade. However, the rate of borrowing of e-resources remains small relative to that of physical materials located at the library. For example, in 2014, circulation of all electronic materials represented $4.7 \%$ of the total circulation for the public library of interest. Considering the U.S. as a whole in the same year, only $56 \%$ of public library systems had electronic material circulated, and of those that had any circulated, these materials represented, on average, $5.2 \%$ of total circulation (Institute of Museum and Library Sciences, 2014). Thus, for this community and, more generally, for U.S. communities, patrons' demand for public library materials is vastly represented by the

\footnotetext{
2 The U.S. Census Bureau defines a micropolitan area as having an urban core population between 10,000 and 50,000 and consists of one or more counties within which there is high degree of social and economic integration.
} 
circulation of physical materials.

\subsection{Households' public library use longitudinal data}

The patron-level checkout records for nearly every Montana public library system are centrally managed by the Montana State Library using the SirsiDynix software. Each individual library system can access patron-level information, including patrons' checkout counts using the web-platform Director's Station. This program generates usage statistics for each patron that include residential address and historical counts on the number of library items borrowed since the patron's library account creation. For example, a library usage report on January 1, 2015 for patron $i$ with a library account created on January 1, 2010 and a checkout history of 400 implies that between January 1, 2010 and January 1, 2015, the patron checked out a total of 400 items, i.e., the stock of checkouts for this patron over the five-year period is 400. Director's Station reports do not distinguish books from other materials checked out such as periodicals, audio, or video media. The SirsiDynix software is designed intentionally to only store historical counts on patrons' use to safeguard First Amendment rights to freedom of speech and information. ${ }^{3}$

Additionally, to reduce excessive use of the data, batch reports must be manually downloaded by a licensed user, such as a librarian employed by the local public library.

Using patrons' historical counts from two adjoining weeks, an SAS script computes the

\footnotetext{
${ }^{3}$ The Director's Station does not provide information about specific titles or genres of the checked-out items. Personal communications with the American Library Association administrators indicated that this type of information is highly protected by public libraries to ensure confidentiality for their patrons. Additionally, while libraries collect information about patrons' use of other library services such as Internet use or children's programming, these data are only made available at the aggregate library level. Individuals are typically not required to use their library cards to access programming or Internet services and, therefore, this usage information is simply not available. While library cards may be required in some libraries to participate in a program or use the Internet, it is highly unlikely that this data would be retained.
} 
number of items checked out for each patron between weeks, i.e., the flow of items checked out, by taking the difference between the historical number of checkouts in week $t$ and the historical number of checkouts in week $t-1$ for each patron $i .^{4}$

The script then aggregates the patron-level weekly counts to the household level using addresses attached to each patron's card to reduce household-level measurement error. When multiple individuals from the same household have separate cards, these individuals may interchangeably use different cards to check out library materials. For example, during one week, a parent may use their card to check out books for the entire household, including books for children in the household. The following week, a child from the same household may use their card to check out materials. Because specific information on checked out materials is censored and there does not appear to be consistent patterns in which individuals within households use their library cards, the patron-level data are instead aggregated to the household-level. Initial regression analyses using patron-level data indicate similar statistical significances and estimated signs as household-level estimates, but noisier. While not needed for the data collection process, during this step each household's address is geocoded to latitude and longitude to merge to other data sets.

Using this data collection procedure weekly, a household-level weekly panel data set is created on the number of items checked out. All operations associated with downloading, aggregating, and geocoding patrons' public library use data are performed at the public library. Prior to providing access to the final data to researchers, the script removes information that

\footnotetext{
${ }^{4}$ Patrons may check out items for a period of two to four weeks, depending on the type of media and demand. For example, newly acquired media may have a short borrowing period of two weeks after which patrons must pay a late fee. For most items, patrons are allowed to renew once before it must be returned to the library.
} 
would allow the identification of any specific household and replaces the information with a single randomly generated unique household number. Some households in the data never check out an item from the library. These households are removed to ensure some household-level variation for the empirical analysis and this restricts the data set to only those who checked out at least one item during the sample time window.

\subsection{Public school attendance and residential property tax assessment data}

Data from Director's Station are particularly useful because they contain cardholders' residential addresses. As such, the library use information is able to be linked to public school enrollment rosters and residential property tax assessment databases.

First, a data-share agreement with the local public school provides a list of addresses of all public-school enrollees for the 2013-14 and 2014-15 school years, respectively. The datasharing agreement with the local school district does not provide any student-level characteristics, including names, grades, and schools, but for the purposes of this analysis, the public-school data are sufficient for determining which households are classified as those with at least one public school student. Additionally, because these data vary across school years, there is precise identification of when households have a child in the public-school system.

The household-level public library use data are merged to the household's property tax assessment values provided by the publicly available Montana Cadastral system. Specifically, as mentioned above, the households' public library use data are geocoded to match to the geospatial property location recorded in Cadastral. This matching requires a two-step criterion: a distance criterion that minimizes the distance between the geographic coordinates in both of the data sources and a fuzzy match criterion that matches the numeric and character values of each 
address. In this manner, a reasonable proxy of household-level relative socioeconomic class based on property values is developed. In cases when multiple households live at the same address (e.g., an apartment complex), each household is associated with the proportional value of the property tax assessment (e.g., for a duplex, each household is assigned half of the property value). Home values are in 2014 dollars.

\subsection{Additional data for characteristics affecting library use}

In modeling household-level library use, additional factors are considered that are plausibly exogenous to households, but could affect weekly library use. There are four factors of specific focus that are systematic and measurable: a household's distance to the public library, weather characteristics (temperature and precipitation), public community events, and publicschool annual calendars that indicate when schools are in session and on break.

A household's distance to the public library can be interpreted as a proxy for a household's relative cost to visit and check out library materials. Palmer (1981), Hayes and Palmer (1983), Japzon and Gong (2005), Sin and Kim (2008), and Bhatt (2010) show that distance is, on average, negatively associated with households' library demand. As such, the distance between each household and the public library are calculated. Because micropolitan areas are less densely populated, traffic congestion is minimal and, as such, each household's distance to the public library is proportional to the transportation costs the household would incur to visit the library. Allen (2019) details how travel times vary by time of day and weekday.

Weather data are obtained from the U.S. National Oceanic and Atmospheric Administration and represent weekly average temperatures (measured in Fahrenheit) and precipitation (measured in inches) in the micropolitan area. To account for community events - 
which occur in the city's downtown core area and are within one mile of the public library information on the number of downtown events is identified in the local municipal online calendar. The one-mile radius is chosen because it represents the approximate boundary of the downtown core area, within which most community events occur and within which the library is located. Any event that is sponsored or located at the public library is excluded.

The public-school calendars provide the exact dates schools are in session and on break for the micropolitan area's one public school district. As noted above, the public library lies entirely in a single school district, implying that all public schools follow the same school-year schedule. Additionally, there is an extremely limited number of private schools, and all follow the local school district's academic calendar. During the sample period, a school break is defined as any period of two or more consecutive weekdays during which all primary and secondary public schools in the school district are closed, as specified by the school district's calendar. Early releases and other short breaks during which students are required to attend a portion of the day are not considered. There are no breaks due to inclement weather or other reasons during the sample period.

The 2013-14 school year begins on August 27, 2013 and ends on June 10, 2014, during which there are four breaks: fall break (October 17-18), Thanksgiving break (November 27-29), winter break (December 23-January 3), and spring break (March 10-14). The summer break occurs between June 10 and September 2, 2014. The 2014-15 school year begins on September 2, 2014 and ends on June 11, 2015, during which there are the same four breaks: fall break (October 16-17), Thanksgiving break (November 26-28), winter break (December 22-January 2), and spring break (March 9-13). The summer break occurred between June 11, 2015 and August 31, 2015. School breaks during the school year represent $10.8 \%$ of the household weekly 
observations in the sample, the summer break represents $28.3 \%$, and weeks during which school is in session represent the remaining $60.9 \%$.

\subsection{Generalizability of sample}

One concern with these data is that the library and micropolitan area are unique and may not be representative of other communities in the United States. While this is not a concern for future researchers who seek to replicate the methodology of this study, this may be a concern for communities and library systems that seek to use these results as empirical evidence to change public policies and library accessibility.

Due to generalizability of sample not being the main focus of this research, the details on public library system and community comparisons are included in Appendix B. The results of these analyses suggest that there do not appear to be pronounced spatial biases or patterns that suggest the library and community in this study is unrepresentative of many other communities across the United States. In fact, $79 \%$ of communities identified as being similar were classified as either metropolitan or micropolitan statistical areas in the 2010 U.S. Census.

\subsection{Analysis procedure - the baseline library demand model}

Variation in weekly household public library use is empirically estimated by modeling public library checkout rates. The baseline model for a household's demand for library materials, $D_{i t}$, by household $i$ during week $t$ is defined as

Equation (1): Baseline Model

$$
D_{i t}=\beta_{0}+\beta_{1} H_{i, t-z}+\beta_{2} C_{t}+\beta_{3} M_{i}+\beta_{4} V_{i}+\beta_{5} S_{i}+\delta_{i}+\delta_{m}+\delta_{y}+\varepsilon_{i t}
$$


The demand for library materials is estimated using an extensive and intensive measure of $D_{i t}$ : active visits, defined as whether the household checked out at least one item during week $t$, and total checkouts during week $t$. The term $H_{i, t-z}$ represents the number of times household $i$ visited the library to check out items within the previous four weeks, which is used as a measure of habit formation that households may develop in response to library return and renewal policies and their own schedules. The four-week period is chosen because the library in this study requires most media be returned or renewed within four weeks of initial checkout. The data also suggest that patrons have substantial habit formation in the number of items they check out from week to week. The vector $C_{t}$ represents community-level characteristics that vary weekly, e.g., the number of community events, temperature, and precipitation, the terms $\delta_{m}$ and $\delta_{y}$ are month and school-year fixed effects that control for seasonal and yearly variation in library demand, and $\varepsilon_{i t}$ is the idiosyncratic error term. This specification is separately estimated for households without a public school student and those with a student.

Equation (1) represents two household-level specifications. The first characterizes households by explicitly modeling their characteristics, which include the household's distance (in miles) from the library, $M_{i}$, the natural $\log$ of the tax-assessed value of the household's residence, $V_{i}$, and an indicator variable of whether the household has a child attending public school, $S_{i}$. The second specification of equation (1) characterizes households using household fixed effects, $\delta_{i}$. Household fixed effects represent factors associated with households that vary minimally or not at all over the sample period. These factors encapsulate the three explicitly modeled characteristics above in equation (1) but also include aspects for which data are not readily available but are important to account for statistical analysis. These can include a household's access to public transportation, education level of adults in the household, 
preferences toward using public libraries, among many other time-insensitive characteristics that are difficult to explicitly model but can affect a household's library use decisions. When the model includes household fixed effects, it must, by definition, exclude the fixed household characteristics $M_{i}, V_{i}$, and $S_{i}$, because these are inherently included within the fixed effect variable. Often sample selection bias estimates and household fixed effects eliminate this bias.

Equation (1) represents estimation of active visits using a linear probability estimator with heteroskedasticity-robust standard errors. The coefficients in this estimation are interpreted in percent effects. In the second characterization of Equation (1), household-level checkouts measures are a count variable and estimated using a Poisson model specification. Due to the complex covariance matrix structure of a fixed-effects Poisson estimator, standard errors are estimated using a 500-replication bootstrap. The coefficients in this estimation are interpreted in percent effects using the transformation $\left(e^{\beta}-1\right) \times 100 \%$.

The negative binomial model is also considered as a possible count estimator. However, there are some reservations on the appropriateness of using this model. First, there is relatively modest evidence of overdispersion in the data. In such cases, the negative binomial model is less robust to distributional misspecification than the Poisson and may be inconsistent even if the conditional mean is correctly specified in the maximum likelihood estimator (Cameron \& Trivedi 2005, 2009). Additionally, Wooldridge (2010) shows that the fixed effect Poisson estimator has very strong robustness properties for estimating the parameters in the conditional mean. Moreover, Wooldridge (1999) demonstrates that the fixed-effect panel Poisson estimator is consistent under only the conditional mean assumption.

\subsection{Analysis procedure - library demand model across SES and HHs distance to library}


There may be important distinctions and interactions among households' geographical access to the library, socioeconomic status, and whether the household has a child in public school. As such, empirical assessment of these potential differential effects are conducted by including households' distance to library indicator variables, $I\left(0.5 \leq M_{i}<1.0\right), I\left(1.0 \leq M_{i}<2.0\right)$, and $I\left(M_{i} \geq 2.0\right)$ in Equation (1):

Equation (2): Baseline $+\mathrm{SES}+$ Household Distance Model

$$
\begin{aligned}
D_{i t}= & \beta_{0}+\beta_{1} H_{i, t-z}+\beta_{2} C_{t}+\beta_{3} I\left(0.5<M_{i}<1.0\right)+\beta_{4} I\left(1.0 \leq M_{i}<2.0\right)+ \\
& \beta_{5} I\left(M_{i} \geq 2.0\right)+\delta_{m}+\delta_{y}+\varepsilon_{i t}
\end{aligned}
$$

The coefficients of interest are $\beta_{3}-\beta_{5}$ and estimate the change in households' public library use due to being farther away from the library than 0.5 miles. The extended model is estimated for three residential property value subsamples: the lowest quartile, Q1, second and third quartiles, Q2-Q3, and the highest quartile, Q4. Similar to the baseline model, these specifications are estimated for households without a public school student and those with a student.

\subsection{Analysis procedure - library demand model across the school calendar}

Families are provided school calendars well in advance of the school year and know when school breaks occur. As such, it is likely that households with a public school student may change their public library use in anticipation of a school break. For example, a family may check out library materials a week before a school break in anticipation of having to provide children with educational materials during the school break or may skip visiting the library after a break as they already have library items. The potential impacts of school break timing are 
empirically investigated to assess the degree to which households might substitute their use of public libraries between weeks before and after school breaks. That is, households choosing to use the library more before a school break and subsequently reduce their use after the school break, or vice versa.

The baseline model, Equation (1), is extended with lag and lead binary indicator variables are added to characterize household-level library use before, during, and after school breaks. Specifically, the two-weeks pre- and post-school year breaks are assessed by including five

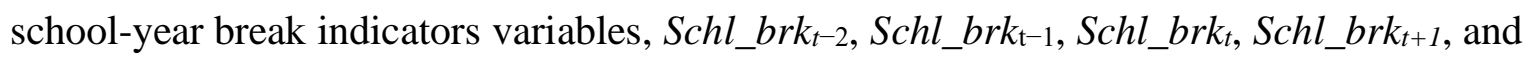
Schl_brkt+2. Due to the substantial length of the summer break, using a similar time indexing approach would not provide useful insights. Instead, differential impacts across the summer are tested using two distinct time periods associated with the summer break: a two-week period immediately preceding the beginning of the school year and a two-week period immediately following the end of the school year using indicator variables, Sum_brk_start $t$ and Sum_brk_end . Including these variables into the baseline model:

Equation (3): Baseline + School Breaks Periods Model

$$
\begin{aligned}
D_{i t}= & \beta_{0}+\beta_{1} H_{i, t-z}+\beta_{2} C_{t}+\beta_{3} M_{i}+\beta_{4} V_{i}+\beta_{5} S_{i}+ \\
& \beta_{6} S c h l_{-} b r k_{t-2}+\beta_{7} S c h l_{-} b r k_{t-1}+\beta_{8} S c h l_{-} b r k_{t}+\beta_{9} S c h l_{-} b r k_{t+1}+\beta_{10} S c h l_{-} b r k_{t+2}+ \\
& \beta_{11} S_{u m} \text { start }_{t}+\beta_{12} S_{u m} \text { end }{ }_{t}+\delta_{i}+\delta_{m}+\delta_{y}+\varepsilon_{i t}
\end{aligned}
$$

The coefficients of interest are $\beta_{6}-\beta_{12}$ and estimate the change in households' public library use due to a school-year or summer break relative to library use within the same month. The separation within the summer break provides an opportunity to test for differential impacts associated with the availability of competing non-school activities. For example, families may find visits to the library are squeezed out by competing alternative activities, such as family 
vacations, summer camps, or participation in outdoor recreational activities. However, because many activities may not begin immediately following a school year and typically do not immediately precede the beginning of a new academic year, differential school break effects on library use may occur during these intermediate periods. These effects could be veiled if the entire summer break is considered as a single break.

Lastly, indicator variables for four specific breaks during the school year are included: October (fall) break, Thanksgiving (November) break, Christmas (December) break, and spring (mid-March) break.

Equation (4): Baseline + Specific School Breaks Model

$$
\begin{aligned}
D_{i t}= & \beta_{0}+\beta_{1} H_{i, t-z}+\beta_{2} C_{t}+\beta_{3} M_{i}+\beta_{4} V_{i}+\beta_{5} S_{i}+ \\
& \beta_{6} \text { Oct_brk }{ }_{t}+\beta_{7} N o v \_b r k_{t}+\beta_{8} D e c \_b r k_{t}+\beta_{9} M a r_{-} b r k_{t}+ \\
& \beta_{10} \text { Sum_start }_{t}+\beta_{11} \text { Sum_end }_{t}+\delta_{i}+\delta_{m}+\delta_{y}+\varepsilon_{i t}
\end{aligned}
$$

\section{Findings}

\subsection{Data summary}

The Director's Station patron reports are downloaded every Tuesday between August 20, 2013 and May 19, 2015 by a librarian at the local public library. ${ }^{5}$ Using the above data construction process, the final panel describes 92 weeks of information on 10,168 households, represented by 560,247 household-weekly observations. The sample consists of $34.8 \%$ of households with children enrolled in the public school and little variation in this portion is observed between school years. The panel is not perfectly balanced as new households enter and

\footnotetext{
5 Tuesdays were chosen to align with the local public school calendar that had set the first day of school on the last Wednesday in August during the 2013-14 school year and the last day of school on the second Tuesday in June.
} 
some exit when their library cards expire and they do not renew during the sample period.

\section{[ Table 1 about here ]}

Table 1 provides descriptive statistics on all variables used in the empirical analyses and presents the data in subsamples to demonstrate the differences between households with and without public school children. The data indicate that, on average, households without children enrolled in public schools visit the public library approximately once a month and check out, on average, 1.29 items per week. However, households with a student check out 1.80 items per week, nearly $28 \%$ more than households without a student. Additionally, households with public school children are, on average, approximately two miles closer to the public library. However, the average home tax value between households with and without public school children are nearly identical. The average weekly temperature is 48.1 degrees Fahrenheit and precipitation is 0.37 inches.

Figure 1 presents time series of average active visits and checkouts by whether the household has a public school child — panels (a) and (b) — and by residential property tax values panels (c) and (d) and provide a few insights. First, the figure shows that households with public school children consistently visit the public library more often and check out more items than households without public school children. This consistent behavior is observed across the entire sample period, despite seasonal variation. Second, the figure provides initial evidence that there may be systematic differences in library demand across the public-school calendar. For example, Figure 1(a) shows that while both groups of households exhibit increases in library visitation during weeks when holidays occur, the increases are somewhat larger for households with students. Moreover, the difference in library visits between the two types of households is at its 
highest throughout weeks that correspond to summer break. Figure 1(b) also shows that households with students increase the number of checked-out items during the summer break, while households without students maintain relatively flat usage throughout the year.

\section{[ Figure 1 about here ]}

Figure 1 also shows weekly active visits and checkouts across the sample period for households in lowest and highest socioeconomic status quartiles - panels (c) and (d). The figure makes evident that households in the lowest quartile of home values consistently visit the library more frequently and check out more materials than households in the highest socioeconomic quartile.

\subsection{Baseline model estimation results}

Table 2 presents estimates of the public library demand model using the active visits and checkouts measures for both households with and without public school children. Each model is estimated with and without household fixed effects. Across all model specifications, the habit formation variable is statistically significant regardless of whether household fixed effects are also included, although their inclusion dampens the magnitude of the estimated coefficient. This coefficient estimate may be interpreted as the change in the probability that a household will visit or check out an item from the public library this week, e.g., households without public school children who visited the library in the past four weeks are 17.1 percent more likely to visit the library this week. This probability diminishes to $8.7 \%$ when the model includes household fixed effects, suggesting estimates without household fixed effects are likely biased. 
Additionally, the results in Table 2 indicate that a larger number of community events occurring near the public library tend to increase the likelihood of a library visit, i.e., each community event increases the likelihood of an active visit by $0.2 \%-0.4 \%$. Average temperature does not affect library use, but higher precipitation during the week substantially increases public library use, with larger effects on households with a public school student. Similar to existing literature, households' distance to the library and residential property tax values are negatively associated with the likelihood of library use; that is, households that incur higher costs and are more affluent are less likely to use the public library as frequently. Moreover, these effects are greater for households with public school children. Lastly, while not shown, the results from an estimation of the baseline model that includes an indicator variable for whether the household has a public-school child shows that, as expected, these households are more likely to use the public library than households without a public-school child (results are available upon request).

\section{[ Table 2 about here ]}

Comparing the active visits results to the checkouts results in Table 2 suggest that distance to library is more important for how often households visit the library than the number of items checked out, and especially so for households with public school children. Also, the results show that there are no differences in checkouts associated with a household's home value.

\subsection{Robustness analyses to ensure consistent baseline model results}

Several robustness analyses are conducted to determine the sensitivity of the estimation results to various specification changes. Because there are a number of different statistical methods that may be proposed to estimate households' behaviors toward public library use, 
robustness analyses are helpful to ensure that the empirical results reported in this paper are consistent across the different statistical methods. The objective of these robustness analyses is to demonstrate whether different methodological approaches applied to the same data lead to the same insights, which would add credence to the results and, ultimately, increase the confidence of decision-makers that the results and subsequent conclusions can be used for making management decisions.

First, the baseline model includes a habit-formation variable to account for behavioral inertia in how households use the library. However, there can be different ways that this habit formation could be defined methodologically. As such, it is important to ensure that the definition of the habit formation variable does not affect the overall empirical results. To test this sensitivity, Equation (1), Baseline Model is estimated for eight different household habitformation variables: one- to four-week lags of active visits and lagged circulation, respectively. Each of the eight specifications is estimated separately for the active visits and checkout measures for households with and without public school children for a total of 32 estimations. Table A1 in the appendix presents the estimation results for these alternative specifications. The results show that the habit-formation variable is always statistically significant in explaining public library use and there is minimal variation in coefficient magnitudes. However, models with the habit-formation variable specified using active visits in the previous four weeks always result in the best model fit.

The second robustness analysis considers changes to the Poisson estimator, which is the preferred estimation method. Similar to changes in the definition and creation of specific variables, the methods by which households' behaviors toward public library use are modeled can also potentially alter the results. To determine whether this is the case, the fully specified 
baseline library demand model is estimated using ordinary least squares (OLS) for the checkouts measure. Table A2 Model 1 presents the estimated OLS parameters for all households. ${ }^{6}$ The estimated marginal effects are largely consistent with those in the Poisson specification. However, the log-likelihood value for the Poisson estimator is substantially larger than that of the OLS estimator, suggesting that the Poisson model has a better model fit.

The third robustness analysis considers that there is a university in the micropolitan area for which the sample is collected. Almost all universities also have libraries, which are available to students at the university and, with some effort, can be accessed by the public. This could, in turn, alter how much households may want to use the local public library. To determine whether the analysis is sensitive to the inclusion of individuals who are also likely to be college students, the fully specified models of active visits and circulation are re-estimated using a subsample that omits the Census tract that includes the university. Table A2, Models 2 and 3 show that the estimation results for this subsample are nearly identical to those in the analysis that includes all households. The population of public library members who reside within this Census tract are $1.5 \%$ of households in the sample.

\subsection{Public library use estimation results by SES and distance to library}

Table A3 presents summary statistics of active visits and checkouts by residential property tax values quartile, labelled SES, and binned distance to the library. ${ }^{7}$ The data indicate

\footnotetext{
${ }^{6}$ The ordinary least squares (OLS) estimator is a commonly used statistical and econometric regression model. Because this model is used to assess the robustness of the empirical results rather than as the primary methodological approach, the specific details about the model are omitted. The OLS statistical model is particularly powerful as it is the best, linear, unbiased estimator.

${ }^{7}$ For a more effective summarization of the distance between a household and the library, households are first allocated into four bins: those located less than 0.5 miles from the library,
} 
that regardless of households' distance to the library, households in the lowest SES status quartile, on average, visit the library more frequently and check out more books per week. This distinction is particularly visible for households within two miles of the public library and tends to dissipate for households that are not within walking distance of the library. Furthermore, the distinctions across households' socioeconomic status and distance are of greater magnitude for households with public school students.

\section{[ Table 3 about here ]}

Table 3 presents the estimation results of Equation (2) for active visits and checkouts measures. For the active visits model, the broad insights are that households without a public school student are particularly sensitive to distance, but this sensitivity is substantially dampened for households with a public school student. For the former group of households, living farther away from the public library tends to be associated with a lower frequency of library visits. Additionally, this behavior is strongest among households in the lowest socioeconomic quartile. The negative relationship between visits and distance is also evident for the highest socioeconomic quartile. Households in the middle two socioeconomic status quartiles appear to be insensitive to distance. Households with a public school student that live within a mile of the public library are more likely to visit, but the largest use is by those in the lowest socioeconomic quartile. This positive differential effect dissipates for similar households that are farther away.

Results for the checkouts measure of library use indicate distance is much less a factor in the intensity of library use, i.e., how many items are checked out. For households without public

between 0.5 and 1 mile, between 1 and 2 miles, and over 2 miles from the library. After this binning is complete, the summary statistics of households' active visits and checkouts are calculated within each of the four distance bins. 
school students, only checkouts for those in the highest socioeconomic quartile are negatively affected by distance to the library and only the lowest socioeconomic quartile households between 0.5 and 1.0 miles of the library are positively affected.

\subsection{Public library use estimation results across breaks in school calendar}

Table 4 presents the estimation results of Equations (3) and (4) for households with a public school student and then for households with students who fall into the lowest socioeconomic quartile. The results indicate that, on average, across all households with public school students, public library use increases during periods leading up to a break that occurs within a school year. However, during the school-year break and for one and two weeks after, active visits and checkouts are more likely to be lower than during other weeks throughout the

year. A similar pattern is observed during the two weeks following the end of a school year and the two weeks preceding the beginning of a school year. These increases in active visits and checkouts are substantially larger than those observed during within-school-year breaks. Lastly, the results suggest that the largest impacts on active visits and checkouts occur during the October and Thanksgiving breaks, with no tangible differences in library demand during the Christmas and spring breaks.

\section{[ Table 4 about here ]}

In contrast to the overall results for households with public school students, those households with public school students that fall into the lowest residential property value quartile have distinctly different public library use. These households appear to only alter their public library use leading up to school-year breaks, and no statistically significant differences in library 
use are estimated during summer breaks. Thus, their use appears to be constant across the calendar.

\section{Discussion}

This research builds the existing literature on public library access and use by providing a new methodology and estimation results using substantially more degrees of patron heterogeneity, including children's public-school enrollment, socioeconomic status, geographic constraints, and the timing of school-year breaks. There are several insights that can be gained from this research to aid researchers, local policymakers, and librarians.

First, the results suggest that current literature relying on cross-sectional analysis of specific groups likely suffer from sample selection bias, and future researchers should consider randomized control trials or other causal inference research designs, e.g., panel data analysis that account for unobservable but fixed differences in individuals. Additionally, these results provide important counsel that any future research in this area must carefully consider distributional differences across factors such as households' distance from the library and socioeconomic characteristics rather than focusing on average effects.

Second, the baseline results indicate that households' lack of mobility continues to inhibit library use and is strongest among households in the lowest socioeconomic quartile (even though they are the most frequent users of libraries). Households in the middle two socioeconomic status quartiles appear to be insensitive to distance, while households in the highest quartile have a negative relationship between active visits and distance to library, perhaps indicating the ability of these households to simply privately acquire materials that are available at a public library. These results suggest that transportation costs for some households may be very binding and 
other approaches for targeting these at-risk groups should be part of a library's outreach programs. Interestingly, the results suggest that once the decision is made to visit the library, the overall demand for library materials is not particularly sensitive to the household's relative location.

Third, the baseline results suggest that there are potential spillover effects between community events and public library use. That is, public library use tends to be higher during periods when concurrent nearby community events are occurring. This may make possible opportunities for public libraries to increase awareness and use of library materials through marketing efforts at community events. However, these effects appear to be greater for increasing demand by households without public school children. Concerning students, the results are suggestive that when alternative outdoor activities may be limited due to inclement weather, these households' use of public libraries increases.

\subsection{Household library use across the school calendar}

The results suggest that households with public school children plan for school year breaks and use the public library more frequently and more intensely in the two-week period prior to the break than during and the two-week period afterward. This suggests that households build up an inventory of library materials for use during a school break, and these additional stocks affect households' library use for a significant amount of time after the break. Overall, there is a net increase in library visits and intensity around school breaks.

The results of this research suggest that households may have a high degree of behavioral inertia and/or constraints that result in highly consistent library use throughout the calendar year and even over the summer (for some households). While it is plausible and likely probable that 
parents understand the potential benefits of using public libraries as supplemental education instruments for their children, households are less likely to change their behaviors to take advantage of library resources. This will persist in being a challenge for libraries.

The increase in active visits and checkouts by households with students just after the school year finishes out and prior to school starting indicates a higher degree of substitution between public schools and libraries. That is, during the summer break shoulder seasons, households with public school children may not yet be engaging in activities such as family vacations, camps, and others activities. Libraries can continue to promote summer reading clubs and other educational opportunities, keeping in mind that this is when households are most likely to participate.

\subsection{Households' library use by socioeconomic status}

Lastly, the data indicate that households in the lowest socioeconomic quartile are already the largest consumer of library materials. As such, changes in the academic calendar and other external factors may not be sufficient to alter their behaviors on the margin. Additionally, for lower socioeconomic status households, altering daily routines may be more costly (e.g., inflexible work schedules, high adverse income effects of not attending work) than for higher socioeconomic households. The empirical results suggest that somewhere between the first and second socioeconomic status quartiles, the opportunity costs become sufficiently lower (i.e., cross a threshold) such that families become more likely to use public libraries during schoolyear and summer breaks. It is certainly possible that a portion of the lower socioeconomic population participates in other summer programs, which could act as substitutes for attending the library. However, for the area of study, there is little evidence of either these possibilities. 
There are few summer camp opportunities, and costs for those that are made available by the municipality are between $\$ 245$ and $\$ 350$ per week (which likely represents a substantial portion of disposable income for lower SES households). In summer programs for which costs are subsidized, enrollment is limited and the demand far outpaces available openings.

\subsection{Strategies for pushing and pulling households to the library}

This research offers practical guidance for developing strategies to increase the demand and use of public library resources. Specifically, libraries can engage in "pull" initiatives that directly market the benefits of library use to households and "push" campaigns that nudge patrons to alter their extensive and intensive demands. Two examples of "pull" initiatives by public libraries might include mobilizing library resources, such as bookmobiles that travel to different locations in a community to provide more limited library resources and programs, and/or establishing increased promotion of library programs (or even temporary branches at targeted public schools) during summer breaks.

"Push" initiatives may provide additional cost-effective methods for using established infrastructures to encourage public library use. For example, public schools can increase informational campaigns about local library materials and programs in weeks preceding a school break and with intermittent electronic communications throughout a summer break. Such "push" strategies that encourage human capital accumulation would be akin to nudges that have been shown in the behavioral economics literature to be successful in increasing financial accumulation in savings and retirement accounts and health outcomes (for example, see Thaler \& Benartzi, 2004; Blumenthal-Barby \& Burroughs, 2012; Liu, Wisdom, Roberto, Liu, \& Ubel, 2014). The empirical results suggest that such "push" campaigns may be particularly useful 
during community events. That is, evidence of positive spillover effects between public events and library use could potentially be leveraged to increase community-based investments to expand the use of library resources.

\section{Conclusion}

This research extends the existing empirical literature on public library use by creating a new data collection process and demonstrating how to merge patron data with other local data sets to provide richer empirical analyses on distribution differences. This new methodology provides insights into the heterogeneous nature of patrons and how familial structure, socioeconomic status, community events, weather, and school calendars impact public library use relationships. As public libraries continue to transition from a summer reading to summer learning focus, a similar methodology could be applied to assess to what extent strategically timed library-based children's programming can be used to build long-term relationships between libraries and their communities. This research did not collect data that would enable this type of assessment, but it is an area ripe for future research consideration and need. 


\section{References}

Agosto, D., Paone, K., \& Ipock, G. (2007). The female-friendly public library: Gender differences in adolescents' uses and perceptions of U.S. public libraries. Library Trends, 56(2), 387-401.

Allen, J. (2019). Mapping differences in access to public libraries by travel mode and time of day. Library Information Science Research, 41(1), 11-18.

Alexander, K., Entwisle, D., \& Olson, L. (2007). Summer learning and its implications: insights from the beginning school study. New Directions for Youth Development, 114, 11-32.

Bhatt, R. (2010). The impact of public library use on reading, television, and academic outcomes. Journal of Urban Economics, 68(2), 148-166.

Bishop, A., Tidline, T., Shoemaker, S., \& Salela, P. (1999). Public libraries and networked information services in low-income communities. Library \& Information Science Research, 21(3), 361-390.

Blumenthal-Barby, J., \& Burroughs, H. (2012). Seeking better health care outcomes: The ethics of using the nudge. American Journal of Bioethics, 12(2), 1-10.

Bogel, G. (2012). Public library summer reading programs contribute to reading progress and proficiency. Evidence Based Library and Information Practice, 7(1), 102-104.

Burke, S. (2007). The use of public libraries by Native Americans. Library Quarterly, 77(4), 429-461.

-. (2008). Use of public libraries by immigrants. Reference \& User Services Quarterly, 48(2), 164-174.

Cahill, M., Soohyung, J., \& Howard, M. (2019). Citizens of the world? Children's exposure to representations of diversity, topics, text genres, and complex ideas prior to kindergarten 
entry. In J.L. Branch-Mueller (ed.), Proceedings of the 48th Annual Conference of the International Association of School Librarianship and the 23rd International Forum on Research in School Librarianship, (pp. 1-10). Edmonton, Canada: University of Alberta.

Cameron, C., \& Trivedi, P. (2005). Microeconometrics: Methods and Applications. Cambridge University Press. Cambridge, UK.

—. 2009. Microeconometrics Using Stata, vol. 5. Stata Press. College Station, TX.

Chen, P., Rea, C., Shaw, R, \& Bottino, J. (2016). Associations between public library use and reading aloud among families with young children. Journal of Pediatrics, 173, 221-227.

Clark, C., \& Hawkins, L. (2011). Public Libraries and Literacy: Young People's Reading Habits and Attitudes to Public Libraries, and an Exploration of the Relationship between Public Library Use and School Attainment. National Literacy Trust. London, England. Retrieved from https://eric.ed.gov/?id=ED515944.

Cooper, H., Nye, B., Charlton, K., Lindsay, J. \& Greathouse, S. (1996). The effects of summer vacation on achievement test scores: A narrative and meta-analytic review. Review of Educational Research, 66(3), 227-268.

Cornelius, P., \& Semmel, M. (1982). Effects of summer instruction on reading achievement regression of learning disabled students. Journal of Learning Disabilities, 15(7), 409-413.

Downey, D., von Hippel, P., \& Broh, B. (2004). Are schools the great equalizer? Cognitive inequality during the summer months and the school year. American Sociological Review, 69(5), 613-635.

Gershenson, S. (2013). Do summer time-use gaps vary by socioeconomic status? American Educational Research Journal,50(6), 1219-1248. 
Goldhor, H., \& McCrossan, J. (1966). An exploratory study of the effect of a public library summer reading club on reading skills. Library Quarterly, 36(1), 14-24.

Goulding, A., \& Crump, A. (2017). Developing inquiring minds: Public library programming for babies in Aotearoa New Zealand. Public Library Quarterly, 36(1), 26-42.

Hayes, R., \& Palmer, S. (1983). The effects of distance upon use of libraries: Case studies based on a survey of users of the Los Angeles Public Library - Central Library and Branches. Library \& Information Science Research, 5(1), 67-100.

Hemmeter, J. (2006). Household use of public libraries and large bookstores. Library \& Information Science Research, 28(4), 595-616.

Heyns, B. (1978). Summer learning and the effects of schooling. Academic Press.

Hodgetts, D., Stolte, O., Chamberlain, K., Radley, A., Nikora, L., Nabalarua, E., \& Groot, S. (2008). A trip to the library: Homelessness and social inclusion. Social \& Cultural Geography, 9(8), 933-953.

Institute of Museum and Library Sciences (2014). Public Libraries Surveys. Washington, D.C. Retreived from https://www.imls.gov/research-evaluation/data-collection/publiclibraries-survey/explore-pls-data/pls-data.

— 2015. Public Libraries Surveys. Washington, D.C. Retrieved from https://www.imls.gov/research-evaluation/data- collection/public-librariessurvey/explore-pls-data/pls-data.

Japzon, A., \& Gong, H. (2005). A neighborhood analysis of public library use in New York City. Library Quarterly, 75(4), 446-463.

Joo, S., \& Cahill, M. (2019). The relationships between the expenditures and resources of public libraries and children's and young adults' use: An exploratory analysis of 
Institute of Museum and Library Services public library statistics data. Journal of Librarianship and Information Science, 51(2), 307-316.

Kewish, L. (1979). Occupational therapists in early intervention programmes in the community. Australian Occupational Therapy Journal, 26(3), 129-138.

Kim, J. (2004). Summer reading and the ethnic achievement gap. Journal of Education for Students Placed at Risk, 9(2), 169-188.

Kronus, C. (1973). Patterns of adult library use: a regression and path analysis. Adult Education, 23(2), 115-131.

Liu, P., Wisdom, J., Roberto, C., Liu, L., \& Ubel, P. (2014). Using behavioral economics to design more effective food policies to address obesity. Applied Economic Perspectives and Policy, 36(1), 6-24.

Madrigal, P., Cubillas, C., Yaden, D., Anamarie, T., Brassell, D., \& Tam, A. (1999). Creating a Book Loan Program for Inner-City Latino Families (No. CIERA-R-2-003). Center for the Improvement of Early Reading Achievement. Ann Arbor, MI. Retrieved from https://pdfs.semanticscholar.org/4aba/6d2e5797887cc52665d937d9470a0fa0e289.pdf

McKenzie, P., \& Stooke, R. (2012). Making a difference. Children and Libraries, 10(2), 47-52. Merga, M., \& Roni, S. (2017). Choosing strategies of children and the impact of age and gender on library use: Insights for librarians. Journal of Library Administration, 57(6), 607-630.

Palmer, S. (1981). The effect of distance on public library use: a literature survey. Library Research, 3(4), 315-354.

Park, S. (2012). Measuring public library accessibility: A case study using GIS. Library \& Information Science Research, 34(1), 13-21.

Peterson, S., Jang, E., Jupiter, C., \& Dunlop, M. (2012). Preschool early literacy programs in 
Ontario public libraries. Partnership: The Canadian Journal of Library and Information Practice and Research, 7(2), 1-21.

Quinn, D. (2015). Black-white summer learning gaps: Interpreting the variability of estimates across representations. Educational Evaluation and Policy Analysis, 37(1), 50-69.

Sin-Ching, J. (2012). Modeling the impact of individuals' characteristics and library service levels on high school students' public library usage: A national analysis. Library \& Information Science Research, 34(3), 228-237.

Sin, S., \& Kim, K. (2008). Use and non-use of public libraries in the information age: A logistic regression analysis of household characteristics and library services variables. Library \& Information Science Research, 30(3), 207-215.

Thaler, R., \& Benartzi, S. (2004). Save more tomorrow: Using behavioral economics to increase employee saving. Journal of Political Economy, 112, S164-S187.

Vårheim, A. (2011). Gracious space: Library programming strategies towards immigrants as tools in the creation of social capital. Library \& Information Science Research, 33(1), 1218.

Wooldridge, J. (1999). Distribution-free estimation of some nonlinear panel data models. Journal of Econometrics, 90, 77-97.

—. 2010. Econometric Analysis of Cross Section and Panel Data. MIT press. Cambridge, MA. 


\section{Tables and Figures}

Table 1

\begin{tabular}{|c|c|c|c|c|}
\hline \multicolumn{5}{|l|}{ Summary statistics } \\
\hline & \multicolumn{2}{|c|}{ HHs w/o students } & \multicolumn{2}{|c|}{ HHs w/ students } \\
\hline & Mean & Std. Dev. & Mean & Std. Dev. \\
\hline \multicolumn{5}{|l|}{ Dependent variables } \\
\hline Active visit & 0.25 & - & 0.27 & - \\
\hline Checkout & 1.29 & 3.17 & 1.80 & 3.98 \\
\hline \multicolumn{5}{|l|}{ Independent variables } \\
\hline Community events & 2.70 & 1.95 & 2.70 & 1.95 \\
\hline Temperature & 48.06 & 18.17 & 48.06 & 18.17 \\
\hline Precipitation & 0.37 & 0.36 & 0.37 & 0.36 \\
\hline Distance to library & 4.73 & 4.65 & 2.88 & 2.14 \\
\hline Log(property values) & 37.79 & 46.07 & 37.59 & 40.73 \\
\hline School-year break & - & - & 0.13 & - \\
\hline Summer break & - & - & 0.15 & - \\
\hline Observations & \multicolumn{2}{|c|}{370,668} & \multicolumn{2}{|c|}{189,579} \\
\hline
\end{tabular}

Notes: Standard deviations omitted on binary indicator variables. 
Table 2

Estimation of $\mathrm{HH}$ public library use

\begin{tabular}{|c|c|c|c|c|c|c|c|c|}
\hline \multirow[b]{3}{*}{ Active visit in past 4 weeks } & \multicolumn{4}{|c|}{ Active visits } & \multicolumn{4}{|c|}{ Checkouts } \\
\hline & \multicolumn{2}{|c|}{ HHs w/o students } & \multicolumn{2}{|c|}{ HHs w/ students } & \multicolumn{2}{|c|}{ HHs w/o students } & \multicolumn{2}{|c|}{ HHs w/ students } \\
\hline & $0.087^{* * *}$ & $0.171^{* * *}$ & $0.080^{* * *}$ & $0.174^{* * *}$ & $0.315^{\star \star \star}$ & $0.323^{* * *}$ & $0.255^{\star * \star}$ & $0.262^{* * *}$ \\
\hline & $(0.001)$ & $(0.001)$ & $(0.002)$ & $(0.001)$ & $(0.007)$ & $(0.013)$ & $(0.009)$ & $(0.015)$ \\
\hline \multirow[t]{2}{*}{ Community events } & $0.003^{* * *}$ & $0.004^{\star * \star}$ & $0.002^{* \star *}$ & $0.003^{* \star *}$ & $0.023^{\star \star *}$ & $0.023^{\star \star \star}$ & $0.017^{\star \star \star}$ & $0.017^{\star \star \star}$ \\
\hline & $(0.000)$ & $(0.000)$ & $(0.001)$ & $(0.001)$ & $(0.003)$ & $(0.003)$ & $(0.003)$ & $(0.003)$ \\
\hline \multirow[t]{2}{*}{ Temperature } & $-0.000^{* * *}$ & $-0.000^{\star * \star}$ & $-0.000^{\star}$ & $-0.000^{* * *}$ & 0.000 & 0.000 & 0.000 & 0.000 \\
\hline & $(0.000)$ & $(0.000)$ & $(0.000)$ & $(0.000)$ & $(0.000)$ & $(0.000)$ & $(0.001)$ & $(0.001)$ \\
\hline \multirow[t]{2}{*}{ Precipitation } & $0.011^{* * *}$ & $0.024^{* * *}$ & $0.020^{* * *}$ & $0.035^{* * *}$ & $0.035^{\star * *}$ & $0.036^{\star \star *}$ & $0.063^{* * *}$ & $0.064^{* * *}$ \\
\hline & $(0.002)$ & $(0.002)$ & $(0.003)$ & $(0.003)$ & $(0.012)$ & $(0.012)$ & $(0.016)$ & $(0.016)$ \\
\hline \multirow[t]{2}{*}{ Distance to library } & & $-0.001^{* * *}$ & & $-0.003^{* * *}$ & & -0.002 & & $-0.022^{*}$ \\
\hline & & $(0.000)$ & & $(0.000)$ & & $(0.004)$ & & $(0.012)$ \\
\hline \multirow[t]{2}{*}{ Log(home value) } & & 0.000 & & $-0.004^{* \star *}$ & & -0.012 & & -0.003 \\
\hline & & $(0.001)$ & & $(0.001)$ & & $(0.037)$ & & $(0.054)$ \\
\hline $\mathrm{HH}$ fixed effects & Yes & No & Yes & No & Yes & No & Yes & No \\
\hline Month fixed effects & Yes & Yes & Yes & Yes & Yes & Yes & Yes & Yes \\
\hline School-year fixed effects & Yes & Yes & Yes & Yes & Yes & Yes & Yes & Yes \\
\hline Observations & 370,668 & 370,668 & 189,579 & 189,579 & 370,668 & 370,668 & 189,579 & 189,579 \\
\hline Log likelihood & $-117,296$ & $-134,774$ & $-65,305$ & $-74,782$ & $-537,056$ & $-561,982$ & $-348,691$ & $-362,056$ \\
\hline
\end{tabular}

Notes: ${ }^{*} p<0.1,{ }^{* *} p<0.05,{ }^{* * *} p<0.01$. 
Table 3

Estimation of $\mathrm{HH}$ public library use by SES and distance to library

\begin{tabular}{|c|c|c|c|c|c|c|c|c|}
\hline \multirow[b]{3}{*}{ SES quartile: } & \multicolumn{8}{|c|}{ Active visits } \\
\hline & \multicolumn{4}{|c|}{ HHs w/o students } & \multicolumn{4}{|c|}{ HHs w/ students } \\
\hline & All & Q1 & Q2-Q3 & Q4 & All & Q1 & Q2-Q3 & Q4 \\
\hline \multirow[t]{2}{*}{0.5 to 1 mile } & $-0.011^{* * *}$ & $-0.019 * * *$ & -0.001 & $-0.020^{\star \star \star}$ & $0.022^{* * *}$ & $0.038^{* * *}$ & $0.011^{*}$ & $0.028^{* * *}$ \\
\hline & $(0.003)$ & $(0.006)$ & $(0.004)$ & $(0.006)$ & $(0.005)$ & $(0.009)$ & $(0.006)$ & $(0.010)$ \\
\hline \multirow[t]{2}{*}{1 to 2 miles } & $-0.008^{* * *}$ & $-0.021^{* * *}$ & 0.003 & $-0.019^{\star \star \star *}$ & 0.004 & 0.011 & -0.002 & 0.011 \\
\hline & $(0.003)$ & $(0.005)$ & $(0.004)$ & $(0.006)$ & $(0.004)$ & $(0.007)$ & $(0.005)$ & $(0.009)$ \\
\hline \multirow[t]{2}{*}{$2+$ miles } & $-0.016^{* * *}$ & $-0.030^{* * *}$ & -0.005 & $-0.019^{* * *}$ & $-0.012^{* * *}$ & -0.006 & $-0.018^{* * *}$ & -0.006 \\
\hline & $(0.003)$ & $(0.005)$ & (0.004) & $(0.006)$ & $(0.004)$ & $(0.007)$ & $(0.005)$ & $\frac{(0.008)}{16.020}$ \\
\hline Observations & 370,668 & 99,262 & 178,333 & 93,073 & 189,579 & 40,962 & 101,785 & $\begin{array}{r}46,832 \\
-18,440\end{array}$ \\
\hline Log likelihood & $-134,785$ & $-35,875$ & $-65,344$ & $-33,510$ & $-74,726$ & $-15,325$ & $-40,886$ & $-18,440$ \\
\hline
\end{tabular}

Checkouts

\begin{tabular}{|c|c|c|c|c|c|c|c|c|}
\hline \multirow[b]{3}{*}{ SES quartile: } & \multicolumn{8}{|c|}{ Checkouts } \\
\hline & \multicolumn{4}{|c|}{ HHs w/o students } & \multicolumn{4}{|c|}{ HHs w/ students } \\
\hline & All & Q1 & Q2-Q3 & Q4 & All & Q1 & Q2-Q3 & Q4 \\
\hline \multirow[t]{2}{*}{0.5 to 1 mile } & -0.116 & -0.067 & -0.018 & $-0.429^{* *}$ & $0.312^{* *}$ & $0.432^{*}$ & 0.166 & 0.300 \\
\hline & $(0.086)$ & $(0.183)$ & $(0.119)$ & $(0.168)$ & $(0.122)$ & $(0.248)$ & $(0.171)$ & $(0.228)$ \\
\hline \multirow[t]{2}{*}{1 to 2 miles } & $-0.139^{*}$ & -0.1 & -0.028 & $-0.460^{\star \star *}$ & 0.122 & 0.077 & 0.093 & 0.18 \\
\hline & $(0.075)$ & $(0.121)$ & $(0.108)$ & $(0.165)$ & $(0.109)$ & $(0.219)$ & $(0.159)$ & $(0.203)$ \\
\hline \multirow[t]{2}{*}{$2+$ miles } & -0.076 & -0.063 & 0.028 & $-0.304^{\star *}$ & -0.006 & 0.003 & -0.038 & 0.056 \\
\hline & $(0.069)$ & $(0.108)$ & $(0.104)$ & $(0.143)$ & $(0.101)$ & $(0.207)$ & $(0.148)$ & $(0.175)$ \\
\hline Observations & 370,668 & 99,262 & 178,333 & 93,073 & 189,579 & 40,962 & 101,785 & 46,832 \\
\hline Log likelihood & $-561,981$ & $-154,593$ & $-272,248$ & $-133,989$ & $-362,048$ & $-78,706$ & $-195,679$ & $-86,625$ \\
\hline
\end{tabular}

Notes: ${ }^{\star} p<0.1,{ }^{* *} p<0.05,{ }^{* \star *} p<0.01$. 
Table 4

\begin{tabular}{|c|c|c|c|c|c|c|c|c|}
\hline & \multicolumn{4}{|c|}{ HHs w/ students } & \multicolumn{4}{|c|}{ HHs w/ students in Q1 SES } \\
\hline & $\begin{array}{l}\text { Active } \\
\text { visits }\end{array}$ & Checkouts & $\begin{array}{c}\text { Active } \\
\text { visits }\end{array}$ & Checkouts & $\begin{array}{l}\text { Active } \\
\text { visits }\end{array}$ & Checkouts & $\begin{array}{l}\text { Active } \\
\text { visits }\end{array}$ & Checkouts \\
\hline \multirow[t]{2}{*}{ Two weeks prior to school-year break } & $0.033^{*}$ & $0.012^{\star * *}$ & - & - & 0.001 & $0.012^{*}$ & - & - \\
\hline & $(0.017)$ & $(0.003)$ & - & - & $(0.035)$ & $(0.007)$ & - & - \\
\hline \multirow[t]{2}{*}{ One week prior to school-year break } & $0.033^{*}$ & $0.014^{* * *}$ & - & - & 0.014 & $0.018^{* * *}$ & - & - \\
\hline & $(0.018)$ & $(0.003)$ & - & - & $(0.034)$ & $(0.007)$ & - & - \\
\hline \multirow[t]{2}{*}{ School-year break } & 0.017 & $-0.008^{* *}$ & - & - & -0.024 & -0.006 & - & - \\
\hline & $(0.019)$ & $(0.003)$ & - & - & $(0.040)$ & $(0.007)$ & - & - \\
\hline \multirow[t]{2}{*}{ One week after school-year break } & 0.005 & $-0.008^{* *}$ & - & - & 0.043 & 0.002 & - & - \\
\hline & $(0.019)$ & $(0.003)$ & - & - & $(0.033)$ & $(0.007)$ & - & - \\
\hline \multirow[t]{2}{*}{ Two weeks after school-year break } & $-0.053^{\star \star \star}$ & $-0.017^{\star \star \star}$ & - & - & -0.01 & -0.006 & - & - \\
\hline & $(0.020)$ & $(0.003)$ & - & - & $(0.038)$ & $(0.007)$ & - & - \\
\hline \multirow[t]{2}{*}{ Two weeks prior to school year end } & $0.169^{\star * \star}$ & $0.022^{* *}$ & $0.163^{* * *}$ & 0.011 & 0.034 & 0.018 & 0.001 & 0.002 \\
\hline & $(0.047)$ & $(0.009)$ & $(0.046)$ & $(0.009)$ & $(0.092)$ & $(0.019)$ & $(0.091)$ & $(0.019)$ \\
\hline \multirow[t]{2}{*}{ Two weeks prior to school year beginning } & $0.199^{\star * *}$ & $0.033^{\star * *}$ & $0.253^{\star * *}$ & $0.084^{\star \star \star}$ & 0.089 & 0.026 & 0.149 & $0.081^{* * *}$ \\
\hline & $(0.048)$ & $(0.009)$ & $(0.047)$ & $(0.009)$ & $(0.102)$ & $(0.019)$ & $(0.102)$ & $(0.019)$ \\
\hline \multirow[t]{2}{*}{ October break } & - & - & $0.091^{\star \star *}$ & $-0.024^{\star * *}$ & - & - & 0.091 & -0.009 \\
\hline & - & - & $(0.035)$ & $(0.007)$ & - & - & $(0.065)$ & $(0.014)$ \\
\hline \multirow[t]{2}{*}{ Thanksgiving break } & - & - & -0.015 & $-0.030^{\star * *}$ & - & - & -0.02 & $-0.030^{* *}$ \\
\hline & - & - & $(0.036)$ & $(0.006)$ & - & - & $(0.069)$ & $(0.012)$ \\
\hline \multirow[t]{2}{*}{ Christmas break } & - & - & 0.011 & 0.000 & - & - & -0.033 & 0.000 \\
\hline & - & - & $(0.024)$ & $(0.005)$ & - & - & $(0.047)$ & $(0.010)$ \\
\hline \multirow[t]{2}{*}{ Spring break } & - & - & -0.008 & -0.002 & - & - & $-0.106^{*}$ & $-0.021^{*}$ \\
\hline & - & - & $(0.031)$ & $(0.005)$ & - & - & $(0.063)$ & $(0.011)$ \\
\hline Observations & 189,579 & 189,579 & 189,579 & 189,579 & 40,962 & 40,962 & 40,962 & 40,962 \\
\hline Log pseudolikelihood & $-339,404$ & $-68,681$ & $-361,894$ & $-74,716$ & $-73,635$ & $-14,007$ & $-78,650$ & $-15,330$ \\
\hline
\end{tabular}

Notes: ${ }^{*} p<0.1,{ }^{* *} p<0.05,{ }^{* * *} p<0.01$. 


\section{Figure 1}

Weekly active visits and checkouts, by HH student status and residential property value

(a) Active visits

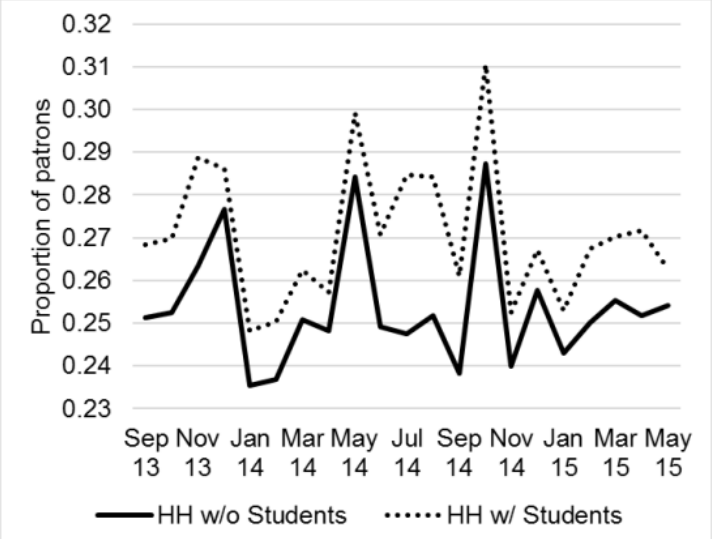

(c) Active visits

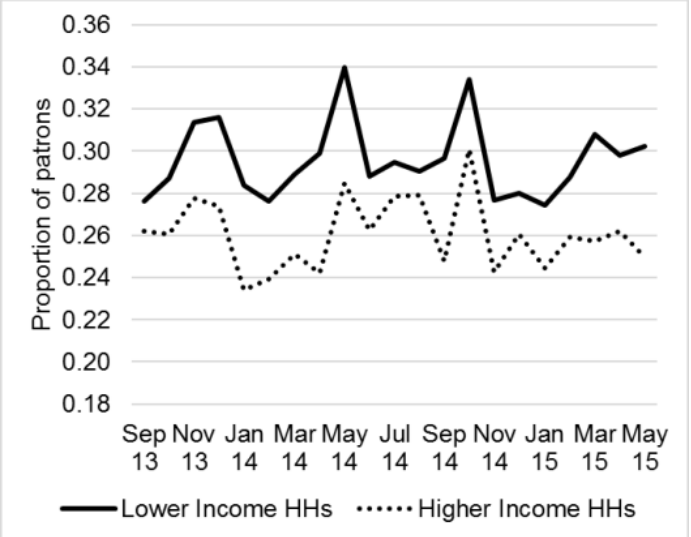

(b) Checkouts

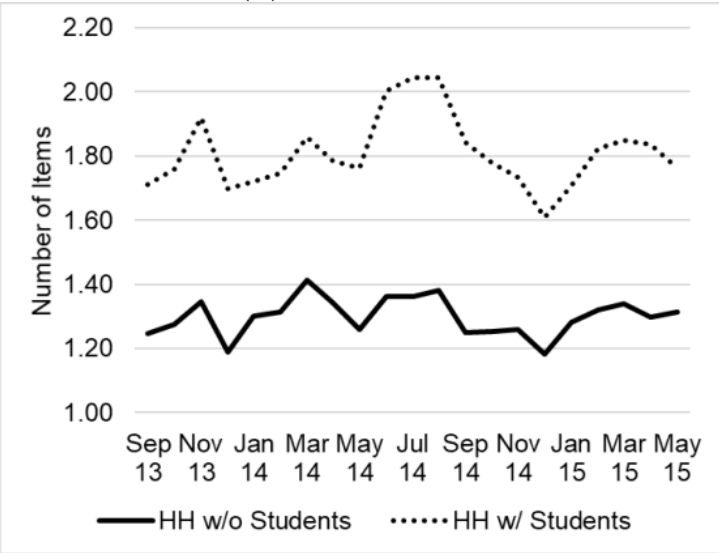

(d) Checkouts

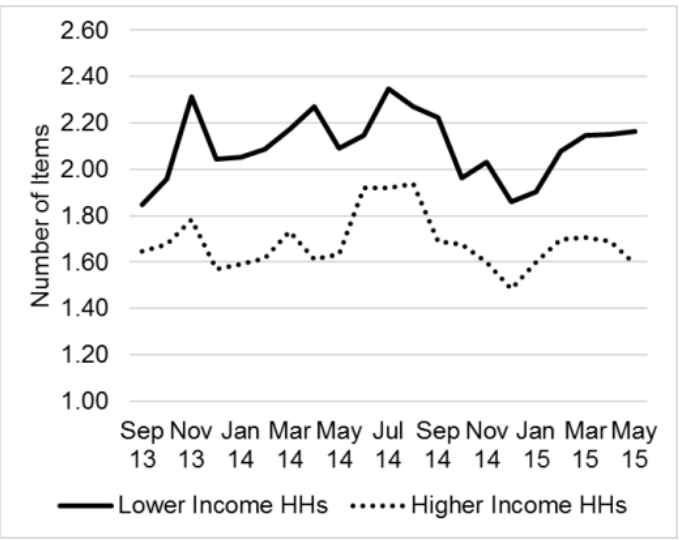

Notes: Active visits and checkouts have been detrended to account for any difference across school years. 


\section{Appendix A}

This appendix provides supplemental tables and figures that accompany the research.

Table A1

HH habit-formation specification sensitivity analysis

\begin{tabular}{|c|c|c|c|c|}
\hline & \multicolumn{2}{|c|}{ HHs w/o students } & \multicolumn{2}{|c|}{$\mathrm{HHs}$ w/ students } \\
\hline & $\begin{array}{l}\text { Active } \\
\text { visits }\end{array}$ & Circulation & $\begin{array}{l}\text { Active } \\
\text { visits }\end{array}$ & Circulation \\
\hline \multirow[t]{3}{*}{ Visited library last week } & $0.146^{* * *}$ & $0.382^{* * *}$ & $0.130^{* * *}$ & $0.248^{* * *}$ \\
\hline & $(0.004)$ & $(0.020)$ & $(0.005)$ & $(0.024)$ \\
\hline & $-122,304$ & $-551,986$ & $-67,400$ & $-355,619$ \\
\hline \multirow[t]{3}{*}{ Number of weeks visited library in last two weeks } & $0.116^{\star \star *}$ & $0.377^{\star \star \star}$ & $0.101^{* * *}$ & $0.264^{\star \star \star}$ \\
\hline & $(0.003)$ & $(0.013)$ & $(0.003)$ & $(0.017)$ \\
\hline & $-120,319$ & $-545,757$ & $-66,755$ & $-353,371$ \\
\hline \multirow[t]{3}{*}{ Number of weeks visited library in last three weeks } & $0.093^{* * *}$ & $0.325^{\star * *}$ & $0.082^{* * *}$ & $0.241^{* * *}$ \\
\hline & $(0.002)$ & $(0.010)$ & $(0.003)$ & $(0.013)$ \\
\hline & $-119,519$ & $-542,721$ & $-66,442$ & $-351,949$ \\
\hline \multirow[t]{3}{*}{ Number of weeks visited library in last four weeks } & $0.087^{\star * *}$ & $0.315^{\star \star \star}$ & $0.080^{\star * *}$ & $0.255^{\star * \star}$ \\
\hline & $(0.001)$ & $(0.007)$ & $(0.002)$ & $(0.009)$ \\
\hline & $-117,296$ & $-537,056$ & $-65,305$ & $-348,691$ \\
\hline \multirow[t]{3}{*}{ Number of items checked out last week } & $0.005^{\star \star \star}$ & $0.006^{\star \star \star}$ & $0.004^{\star \star \star}$ & $0.004^{\star \star \star}$ \\
\hline & $(0.001)$ & $(0.001)$ & $(0.001)$ & $(0.001)$ \\
\hline & $-125,020$ & $-553,737$ & $-68,544$ & $-355,866$ \\
\hline \multirow[t]{3}{*}{ Number of items checked out in last two weeks } & $0.006^{\star * *}$ & $0.008^{* * *}$ & $0.004^{* * *}$ & $0.006^{* * *}$ \\
\hline & $(0.001)$ & $(0.001)$ & $(0.001)$ & $(0.001)$ \\
\hline & $-123,899$ & $-551,743$ & $-68,129$ & $-355,095$ \\
\hline \multirow[t]{3}{*}{ Number of items checked out in last three weeks } & $0.005^{\star * *}$ & $0.007^{* \star *}$ & $0.004^{* * *}$ & $0.006^{* * *}$ \\
\hline & $(0.001)$ & $(0.001)$ & $(0.001)$ & $(0.001)$ \\
\hline & $-123,308$ & $-550,452$ & $-67,925$ & $-354,453$ \\
\hline \multirow[t]{3}{*}{ Number of items checked out in last four weeks } & $0.005^{\star * *}$ & $0.008^{\star * *}$ & $0.004^{\star * *}$ & $0.007^{\star * *}$ \\
\hline & $(0.001)$ & $(0.001)$ & $(0.001)$ & $(0.001)$ \\
\hline & $-122,184$ & $-548,250$ & $-67,287$ & $-352,803$ \\
\hline Observations & 371,606 & 368,776 & 189,954 & 188,953 \\
\hline
\end{tabular}


Table A2

Sensitivity estimations of $\mathrm{HH}$ public library use

\begin{tabular}{|c|c|c|c|}
\hline & Model 1 & Model 2 & Model 3 \\
\hline \multirow[t]{2}{*}{ Active visit in past 4 weeks } & $1.236^{\star \star \star}$ & $0.172^{\star \star \star}$ & $0.299^{\star \star \star}$ \\
\hline & $(0.005)$ & $(0.000)$ & $(0.010)$ \\
\hline \multirow[t]{2}{*}{ Community events } & $0.040^{\star * *}$ & $0.004^{\star * *}$ & $0.020^{\star * *}$ \\
\hline & $(0.003)$ & $(0.000)$ & $(0.002)$ \\
\hline \multirow[t]{2}{*}{ Temperature } & $-0.003^{\star * *}$ & $-0.000^{* * *}$ & 0.000 \\
\hline & $(0.001)$ & $(0.000)$ & $(0.000)$ \\
\hline \multirow[t]{2}{*}{ Precipitation } & $0.195^{\star * *}$ & $0.028^{* * *}$ & $0.050^{\star * *}$ \\
\hline & $(0.015)$ & $(0.002)$ & $(0.010)$ \\
\hline \multirow[t]{2}{*}{ Distance to library } & $0.006^{* * *}$ & $-0.001^{\star * *}$ & $-0.008^{*}$ \\
\hline & $(0.001)$ & 0.000 & $(0.004)$ \\
\hline \multirow[t]{2}{*}{ Log (home value) } & $-0.048^{\star * *}$ & $-0.001^{\star * *}$ & -0.018 \\
\hline & $(0.005)$ & $(0.001)$ & $(0.029)$ \\
\hline \multirow[t]{2}{*}{ Household w/ public school student } & $0.342^{\star * \star}$ & $0.005^{\star * *}$ & 0.103 \\
\hline & $(0.009)$ & $(0.001)$ & $(0.063)$ \\
\hline $\mathrm{HH}$ fixed effects & No & No & No \\
\hline Month fixed effects & Yes & Yes & Yes \\
\hline School-year fixed effects & Yes & Yes & Yes \\
\hline Observations & 560,247 & 552,045 & 552,045 \\
\hline Log likelihood & $-1,434,517$ & $-206,786$ & $-910,415$ \\
\hline
\end{tabular}


Table A3

\begin{tabular}{|c|c|c|c|c|c|c|c|c|}
\hline \multicolumn{9}{|c|}{ Summary statistics on $\mathrm{HH}$ library use by SES and distance to library } \\
\hline & \multicolumn{8}{|c|}{ Active visits } \\
\hline & \multicolumn{4}{|c|}{ HHs w/o students } & \multicolumn{4}{|c|}{ HHs w/ students } \\
\hline SES quartile: & All & Q1 & Q2-Q3 & Q4 & All & Q1 & Q2-Q3 & Q4 \\
\hline All & 0.21 & 0.21 & 0.21 & 0.20 & 0.23 & 0.24 & 0.23 & 0.23 \\
\hline Less than 0.5 miles & 0.25 & 0.28 & 0.22 & 0.25 & 0.24 & 0.24 & 0.25 & 0.23 \\
\hline 0.5 to 1 mile & 0.21 & 0.22 & 0.22 & 0.20 & 0.31 & 0.35 & 0.29 & 0.31 \\
\hline 1 to 2 miles & 0.22 & 0.22 & 0.23 & 0.20 & 0.26 & 0.26 & 0.25 & 0.26 \\
\hline \multirow[t]{3}{*}{$2+$ miles } & 0.20 & 0.20 & 0.20 & 0.20 & 0.21 & 0.21 & 0.21 & 0.21 \\
\hline & \multicolumn{8}{|c|}{ Checkouts } \\
\hline & \multicolumn{4}{|c|}{ HHs w/o students } & \multicolumn{4}{|c|}{$\mathrm{HHs}$ w/ students } \\
\hline SES quartile: & All & Q1 & Q2-Q3 & Q4 & All & Q1 & Q2-Q3 & Q4 \\
\hline All & 1.11 & 1.14 & 1.13 & 1.03 & 1.53 & 1.74 & 1.48 & 1.48 \\
\hline Less than 0.5 miles & 1.29 & 1.41 & 1.15 & 1.41 & 1.45 & 1.49 & 1.57 & 1.06 \\
\hline 0.5 to 1 mile & 1.04 & 1.04 & 1.09 & 0.92 & 2.13 & 3.17 & 1.73 & 1.90 \\
\hline 1 to 2 miles & 1.11 & 1.23 & 1.11 & 0.93 & 1.76 & 1.87 & 1.69 & 1.77 \\
\hline $2+$ miles & 1.10 & 1.10 & 1.14 & 1.04 & 1.38 & 1.43 & 1.36 & 1.38 \\
\hline
\end{tabular}

